\title{
NEURONAL MECHANISMS OF KETAMINE-INDUCED ANESTHESIA
}

\author{
Matué Miyasaka and Edward F. Domino \\ Michigan Neuropsychopharmacology Research Program, \\ Department of Pharmacology, University of Michigan, Ann Arbor, U.S.A.
}

(Accepted 20 May' 1968)

\begin{abstract}
Summary--The sites of action of ketamine (CI-581; 2-(0-chlorophenyl)-2-methylamino cyclohexamine $\mathrm{HCl}$ ) were determined in the central nervous system using electrophysiological techniques in both acute and chronic cat experiments. It was demonstrated in chronic preparations that the cataleptic anesthetic state induced by ketamine is accompanied by an alternating pattern of hypersynchronous delta wave bursts and low voltage, fast wave activity in the neocortex and thalamus. The delta wave bursts had a distribution in the neocortex similar to that of spindles produced by low doses of barbiturates or natural sleep. Subcortically, the delta wave bursts were observed prominently in the thalamus and in the caudate nucleus. The EEG patterns of the diffusely projecting thalamic nuclei were closely related phasically to the delta waves of the neocortex. EEG changes in the midbrain reticular formation and hypothalamus were not as prominent. Paradoxically, the hippocampus showed theta "arousal" waves during the delta wave burst period of the thalamo-neocortical system. This functional dissociation between the thalamo-neocortical and limbic system was one of the EEG characteristics of ketamine.

Ketamine, in contrast to the barbiturates, depressed the recruiting response at a time when neocortical EEG activation was minimally affected. Somatosensory potentials evoked from stimulation of the median nerve were depressed primarily in the nonspecific thalamic nuclei, midbrain reticular formation, somatosensory cortex and sensory relay nuclei, respectively, with minimal anesthetic doses. Multiple neuronal unit activity showed clear grouping in the thalamus. The closest relationship of multiple unit activity to the delta waves in the neocortex was observed in the diffusely projecting thalamic nuclei. After ketamine the reticular formation showed neither grouping nor suppression of multiple unit activity during the neocortical delta bursts. Based upon these observations, the site of action of ketamine in minimal anesthetic doses appears to be in the non-specific thalamo-neocortical system. This system seems to be a primary factor in producing the hypersynchronous delta wave burst pattern in the EEG.
\end{abstract}

\section{INTRODUCTION}

KETAMINE is a potent dissociative anesthetic in both animals (McCARTHY et al., 1965; CHEN et al., 1966; BREE et al., 1967) and man (Domino et al., 1965; CoRSSEN and Domino, 1966; VIRTUE et al., 1967). The drug is a short-acting anesthetic without serious undesirable side effects, such as respiratory or cardiovascular depression. Ketamine produces an emergence delerium in approximately $1 / 3$ of adults (Domino et al., 1965) with a much lower incidence in children (CORSSEN and Domino, 1966). Ketamine has unusual cataleptic features which distinguish it from more common general anesthetics. It is very closely related to phencyclidine (Domino, 1964) in many of its pharmacologic effects. However, because of its shorter duration of action, weaker psychotomimetic effects and being less convulsant, it is superior to phencyclidine as an anesthetic. Current clinical studies suggest that ketamine may become a very useful anesthetic agent, particularly in infants and children. 
It was our purpose to determine the sites of action of ketamine and compare it with barbiturates such as pentobarbital and thiamylal in several neurophysiologic preparations. In addition, a detailed analysis of the mechanism underlying ketamine-induced, hypersynchronous delta wave bursts in the neocortex and thalamus was undertaken.

\section{METHODS}

Experiments were performed in 50 acute and 5 chronic adult cats. The animals weighed between 2.7 and $4 \mathrm{~kg}$. In acute cat experiments, surgery was performed under diethyl ether anesthesia. Wound edges were infiltrated with $1 \%$ xylocaine, the animal paralyzed with decamethonium ( $1 \mathrm{mg} / \mathrm{kg}$, i.v.) and artificially ventilated. Chronic indwelling brain electrodes were placed in various cortical and subcortical areas under pentobarbital anesthesia. Concentric bipolar needle electrodes were used for subcortical recordings. Conventional stainless steel needle tubing, $0.5 \mathrm{~mm}$ with a center wire of $0.22 \mathrm{~mm}$ dia. and insulated except at the tips, was used. The electrodes were implanted with the aid of a stereotaxic apparatus according to the atlases of JASPER and AJMONE-MARSAN (1954) and SNIDER and NiEMER (1961). Location of electrode tips was checked by physiological responses during the experiment and subsequently verified by histological examination. Neocortical electrodes, consisting of two small silver balls of $0.5 \mathrm{~mm}$ dia., were placed visually on the pia matter of the appropriate gyrus. Recruiting responses were elicited from nucleus centrum medianum by electrical stimulation with $8 \mathrm{~Hz}$ square wave pulses of $0.2-0.5 \mathrm{msec}$ and $1 \cdot 5-4.0 \mathrm{~V}$. EEG activation was produced by electrical stimulation of the midbrain reticular formation or nucleus centrum medianum with square wave pulses of $100 \mathrm{~Hz}, 1 \mathrm{msec}$ and $0.7-2.0 \mathrm{~V}$. Somatosensory evoked potentials were recorded monopolarly from the posterior sigmoid gyrus, nucleus ventralis posterior lateralis, nucleus centrum medianum and midbrain reticular formation. Somatosensory evoked potentials were produced by electrical stimulation of the contralateral median nerve via needle electrodes inserted percutaneously. Parameters of electrical stimulation were square wave pulses of $0 \cdot 2-0.3 \mathrm{msec}, 1 \mathrm{~Hz}$ and $1 \cdot 5-5 \cdot 0 \mathrm{~V}$. This usually represented approximately 4 times threshold. Evoked potentials were summated using a CAT computer as the mean of 100 responses. Multiple unit activity was recorded usually monopolarly to the nasion as reference. The corresponding EEG activity was recorded with the same electrode. Multiple unit activity was amplified on one channel of the Grass model III EEG, passed through a spike filter (Kopff SF10-A), and visualized on a dual beam Tecktronics oscilloscope in a similar manner to that of WEBER and BuCHWALD (1965). Multiple unit activity and the corresponding EEG activity were photographed simultaneously using a Polaroid camera. All drugs were administered i.v. in acute preparations and i.p. in the chronic experiments. Doses of $1-16 \mathrm{mg} / \mathrm{kg}$ of ketamine, $5-20 \mathrm{mg} / \mathrm{kg}$ of pentobarbital and thiamylal were given over a 30 -sec period.

\section{RESULTS}

\section{Effects of ketamine on EEG and behavior}

The effects of ketamine in doses of $2-4 \mathrm{mg} / \mathrm{kg}$ i.v. on the EEG of an acute cat is illustrated in Fig. 1. Shortly after injection, delta waves appeared in increasing number in the neocortex, thalamus and caudate nucleus. When an additional dose $(2 \mathrm{mg} / \mathrm{kg}$ or a total of $4 \mathrm{mg} / \mathrm{kg}$ ) was given approximately 3-5 min later, slow waves of higher amplitude appeared more continuously (Fig. 1B, C). Subsequently, the delta waves were interrupted by progressively 
A. CONTROL

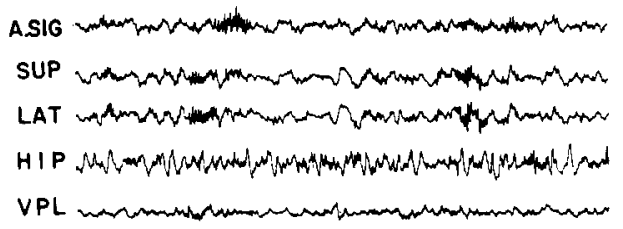

C. 4MIN AFTER 4MG/KG KETAMINE I.V.

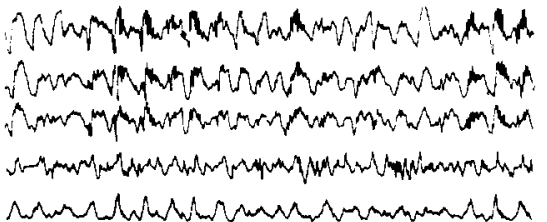

E. 40 MIN AFTER

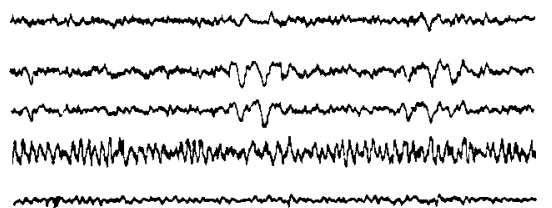

B. 4 MIN AFTER EMG/KG KETAMINE I.V.

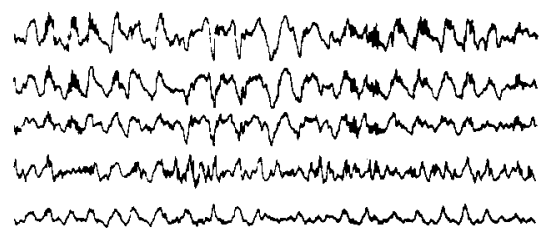

D. 15 MIN AFTER

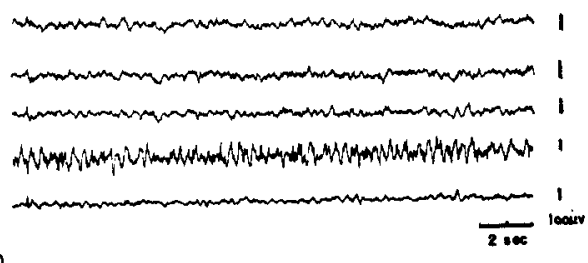

(CATA.O)

F. I HR AFTER

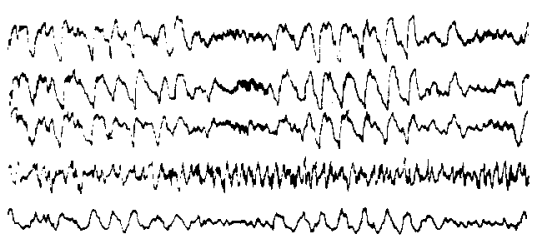

FIG. 1. EEG effects of ketamine.

Panel A. Control EEG tracings of an acute cat preparation. Minimal EEG spindles are observed in the neocortical areas. Panel B. $4 \mathrm{~min}$ after $2 \mathrm{mg} / \mathrm{kg}$ of ketamine i.v. Continuous hypersynchronous delta waves were observed in the neocortical areas. Panel C. $4 \mathrm{~min}$ after an additional $2 \mathrm{mg} / \mathrm{kg}$ of ketamine (4 mg/ $\mathrm{kg}$ total). The EEG effects were somewhat enhanced. Panel D. $15 \mathrm{~min}$ later. Characteristic delta wave bursts interrupted by low voltage, fast frequency activity were observed in the neocortical areas. At this time the hippocampus showed a tendency to develop theta wave "arousal" activity. Panel E. $40 \mathrm{~min}$ after the last dose of ketamine. The EEG of the neocortex showed low voltage, fast wave activity with occasional delta waves, while the hippocampus showed a continuous theta wave activated pattern. Panel F. $1 \mathrm{hr}$ after ketamine administration. EEG showed a general "arousal" pattern both in the neocortical and limbic systems. Bipolar EEG recordings were taken. Symbols for this and subsequent figures are: A.SIG, anterior sigmoid gyrus; SUP, suprasylvian gyrus; LAT, lateral gyrus, HIP, hippcampus, VPL, n. ventralis posterior lateralis. The time base for $2 \mathrm{sec}$ is shown.

The vertical bars represent $100 \mu \mathrm{V}$ calibration.

longer episodes of low voltage, fast wave activity. This produced the characteristic delta wave burst appearance (Fig. 1D), while the hippocampus showed theta "arousal" waves. Approximately 20-45 min after ketamine, delta waves occurred less frequently and were of lower amplitude (see Fig. IE). At this time, more typical hippocampal theta wave activity was observed. About 45-60 min after ketamine administration, the EEG showed generalized activation both in the neocortex and subcortex, although sporadic slow waves still appeared. Approximately $1.0-1.5 \mathrm{hr}$ after $4 \mathrm{mg} / \mathrm{kg}$ of ketamine, the EEG returned to control.

In contrast to the marked delta wave bursts in the neocortex, thalamus and caudate nucleus, prominent delta waves did not appear in the hippocampus, hypothalamus and midbrain reticular formation (see Fig. 1). Hippocampal changes induced by the drug 
usually consisted of an activation pattern in the delta wave burst period of the thalamoneocortical system. Dissociation of the EEG activity between the thalamo-neocortical and the limbic system appears to be one of the more unusual EEG features of this agent.

The behavioral correlates of the prominent EEG changes produced by ketamine were studied in 5 cats with chronic indwelling brain electrodes. Following $2-4 \mathrm{mg} / \mathrm{kg}$ of ketamine i.p., moderate voltage delta waves appeared sporadically in the neocortex and thalamus. The cats retained their resting postures but appeared slightly less attentive to external stimuli. Following 4-8 mg/kg i.p., the alternating pattern of hypersynchronous delta wave bursts and low voltage, fast wave activity was similar to that seen in acute preparations (Fig. 1D). In these doses the continuous delta wave pattern (Fig. 1 B, C) was not observed, and the delta wave bursts were usually shorter in duration and interrupted for longer periods of time by fast activity. Thus the continuous delta wave pattern is not an essential correlate of behavioral anesthesia. The EEG dissociation between the thalamo-neocortical and the limbic system observed in acute animals was also present in chronic preparations. During the hypersynchronous delta wave burst period, the animals crouched flatly on the floor without any significant movement with their heads between their outstretched forelegs. They showed no behavioral responses to external stimuli including ordinarily painful pinches. In contrast with the anesthetic state produced by barbiturates, ketamine-induced anesthesia looked behaviorally quite different. After ketamine, the animal's eyes were kept half open in a fixed gaze, pupils maximally dilated, and the corneal reflex maintained. The animal did not lay on its side as after barbiturates. The EMG of the neck muscles was slightly reduced in amplitude. Respiration was reduced slightly and the heart rate increased.

Twenty or $30 \mathrm{~min}$ after the i.p. injection of ketamine the neocortical delta wave bursts became less frequent, smaller and irregular, while the hippocampus showed a more activated EEG pattern similar to that shown in Fig. 1E. During this period, the cats emerged from anesthesia showing continuous restlessness. They lifted their heads, looked around, tried to stand, walked but were severely ataxic and fell repeatedly. They appeared somewhat confused and excited but inattentive to external stimuli. About 1 or $1.5 \mathrm{hr}$ after ketamine, both EEG and behavior returned almost to control, although the tendency for ataxia persisted for $2 \mathrm{hr}$ or more.

Because of the close relationship between the hypersynchronous delta wave bursts in the EEG and the anesthetic state produced by ketamine, a further analysis of the delta wave bursts and their underlying neuronal mechanisms was undertaken. During the period of maximal EEG effect of i.v. ketamine with continuous delta waves, both biphasic and triphasic delta wave forms were observed, mainly in the neocortical system (see Fig. 1C, Fig. 2A). These patterns were similar in both monopolar and bipolar recordings in the neocortex (Fig. 2A, D). They showed a small negative-positive and large negative slowwave component in the monopolar recording reminding one of a spike-dome complex but somewhat atypical in that the spike was not so sharp. The large slow wave components sometimes were interspersed by fast-frequency bursts of $14-15 \mathrm{~Hz}$ (see Fig. 2B). In the delta wave burst period, the waves had a simple sinusoidal form with a sharp positive cleft followed by a negative slow wave (see Fig. 2D). The typical 8-10 Hz spindle bursts observed in the drowsy state were generally reduced after ketamine.

In the neocortex, the delta waves were more prominent in the anterior half of the suprasylvian, lateral and anterior sigmoid gyri. In contrast, they were poorly developed in the ectosylvian (auditory area) and posterior lateral gyri (visual area) as illustrated in Fig. 3. This distribution of delta waves is somewhat similar to the distribution of spindle bursts 


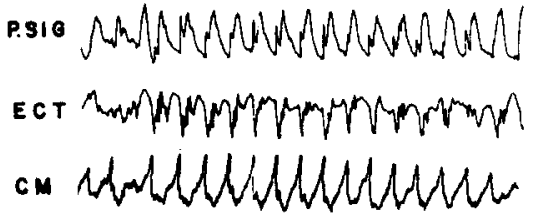

EKO

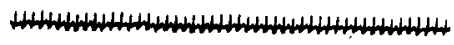

C. BIPOLAR FASTER RECORDING, SMIN.AFTER

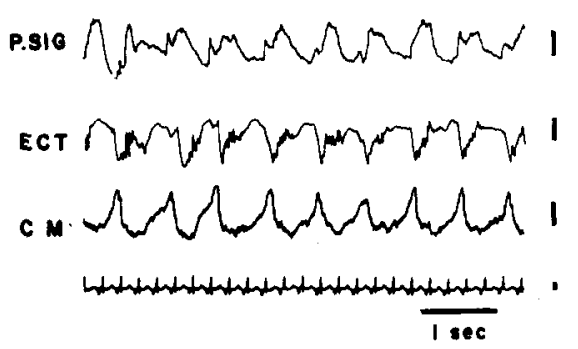

MNANMAMNMNMNA

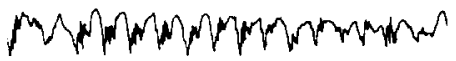

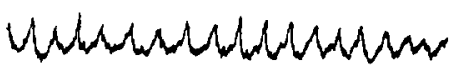

\section{MONOPOLAR RECORDING, IOMIN AFTER}

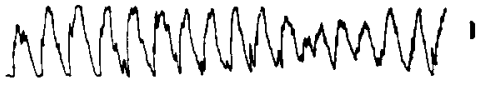

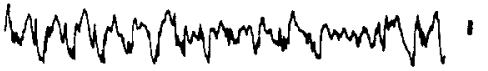

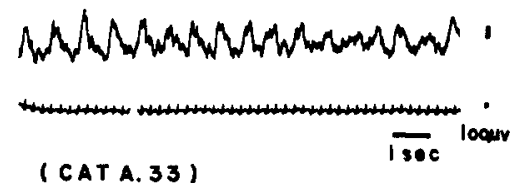

FIG. 2. Phase relationship of ketamine induced EEG slow waves.

EEG recordings were obtained in an acute preparation. Panel A. 5 min after $4 \mathrm{mg} / \mathrm{kg}$ i.v. of ketamine. Bipolar recordings indicate that $n$. centrum medianum has the sharpest slow waves, followed by the round delta waves of the neocortex. Panel B. 10 min after ketamine administration. Panel C. Bipolar recording at a faster speed of 5 min after ketamine administration. Panel D. Monopolar recording $10 \mathrm{~min}$ after ketamine administration. Legends: P.SIG., posterior sigmoid gyrus; ECT, ectosylvian gyrus; CM, $n$. centrum medianum.

A. CONTROL

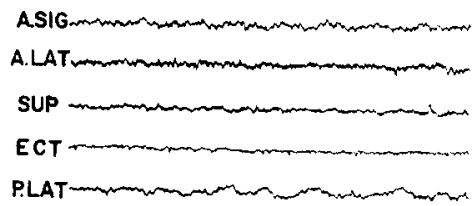

C. I5MIN AFTER

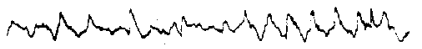

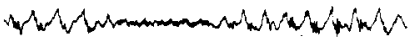

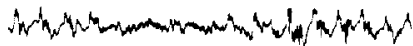

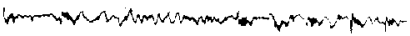

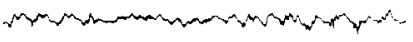

B. 5 MIN AFTER 4MG/KG KETAMINE I.V.

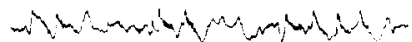

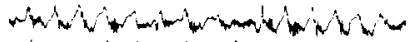

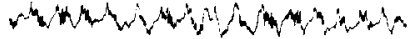

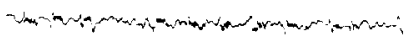

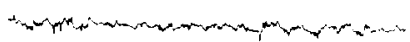

D. I HR AFTER

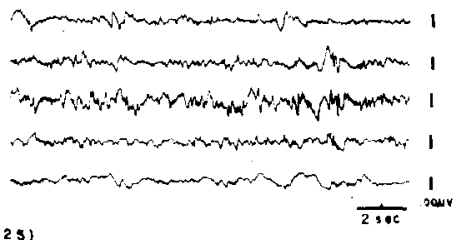

FIG. 3. Neocortical regional differences of ketamine-induced slow waves.

Panel A. Control EEG tracing showing low voltage, fast wave activity in various neocortical areas. Panel B. $5 \mathrm{~min}$ after $4 \mathrm{mg} / \mathrm{kg}$ of ketamine i.v. Note that the delta wave bursts are prominent in the somatomotor (A.SIG) and association areas (A.LAT and SUP) but poorly developed in the primary auditory (ECT) and visual (P.LAT) areas. Panel C. $15 \mathrm{~min}$ after ketamine administration. Note the development of typical delta bursts and a low voltage, fast wave pattern most evident in the association areas (A. LAT and SUP). Panel D. $1 \mathrm{hr}$ later. Partial recovery from ketamine. Note that the association areas still show some slow wave changes. 
observed during spindle wave sleep and following small doses of barbiturates. However, the delta waves appeared more prominently in the association area than in the somatosensory and motor areas.

Subcortically, the slow wave bursts were prominent in the thalamus and caudate nucleus. The clearest and sharpest slow waves occurred in bipolar recordings taken from nucleus centrum medianum and seemed to be followed by delta wave activity in the neocortex. The peaks of the sharp slow waves in nucleus centrum medianum corresponded to the starting point of the large negative slow waves of the neocortex and sensory relay nucleus (see Fig. 2A, C). In nucleus ventralis posterior lateralis and the caudate, the slow waves usually had a more blunt slow-wave form in both monopolar and bipolar recordings but were not necessarily associated with the neocortical waves as closely as those in the diffuse thalamic projection system.

\section{Effects of ketamine in the cerveau isolé preparation}

In this preparation, ketamine produced a similar delta wave pattern in both the neocortex and thalamus as in intact cats (see Fig. 4). However, the delta wave activity was somewhat slower and had a rather continuous appearance without interruption by the low voltage, fast wave activity. Spindle bursts were recorded but reduced in amplitude and duration and interspersed with delta waves. It appeared that the brain stem was not essential for the production of slow waves but was essential for the production of the distinct pattern of slow wave bursts interrupted by low voltage, fast frequency activity.

\section{Effects of ketamine in the subtotal decorticate cat}

In a total of 4 acute decorticate preparations, the EEG activity of the thalamus was recorded from nucleus ventralis posterior and centrum medianum. The EEG usually showed a low voltage, fast wave pattern prior to ketamine administration. After $2-4 \mathrm{mg} / \mathrm{kg}$
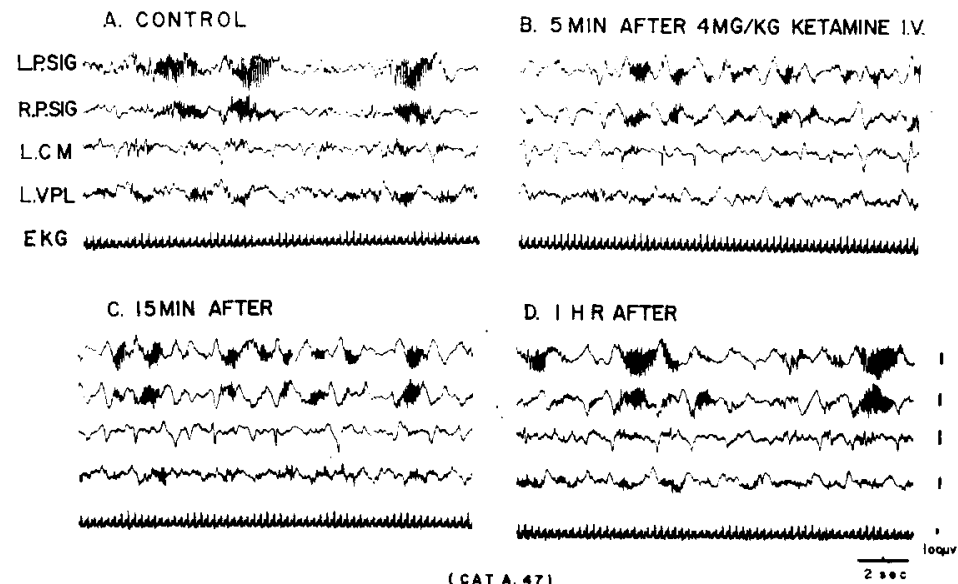

FIG. 4. EEG effects of ketamine in the cerveau isolé preparation.

Panel A. Control EEG recording $2 \mathrm{hr}$ after a classical midbrain transection. Panel B. $5 \mathrm{~min}$ after $4 \mathrm{mg} / \mathrm{kg}$ of ketamine i.v. Note the development of delta wave activity and decrease in spontaneous spindle bursts in the neocortex and sharp slow waves in CM. Panel C. $15 \mathrm{~min}$ after ketamine. Panel D. $1 \mathrm{hr}$ after ketamine. Although there is partial recovery of the amplitude of EEG spindles, delta wave activity tends to persist. Although it is possible for slow waves to occur following ketamine administration in the cerveau isolé, no clear delta wave bursts interrupted by low voltage, fast wave activity are present. 
of ketamine i.v., the delta waves were observed without a clear burst form, suggesting that the neocortex contributes to the production of the burst form of delta waves. After 5-10 $\mathrm{mg} / \mathrm{kg}$ of thiamylal, typical spindle bursts were not clearly observed in these decorticate preparations but the $8-10$ cs activity of spindle-like character was still present.

\section{Effects on neocortical recruiting responses}

The action of ketamine on recruiting responses produced by electrical stimulation of centrum medianum was studied in 12 cats. A dose of $1 \mathrm{mg} / \mathrm{kg}$ of i.v. ketamine depressed neocortical recruitment in 5 of 9 cases. The recruiting response was reduced in 8 of 9 instances with $2 \mathrm{mg} / \mathrm{kg}$ and in all cases with doses of $2-4 \mathrm{mg} / \mathrm{kg}$. A $50 \%$ increase in the control threshold did not overcome the induced depression of the recruiting response following $2-4 \mathrm{mg} / \mathrm{kg}$ of ketamine. In contrast to the dramatic depressant effects of ketamine on recruiting responses, $5-20 \mathrm{mg} / \mathrm{kg}$ i.v. of pentobarbital consistently enhanced neocortical recruitment in 5 animals. Typical records of these opposite effects of ketamine and pentobarbital on the recruiting response in the same animal are illustrated in Fig. 5 after a suitable interval for recovery from ketamine.

A. CONTROL

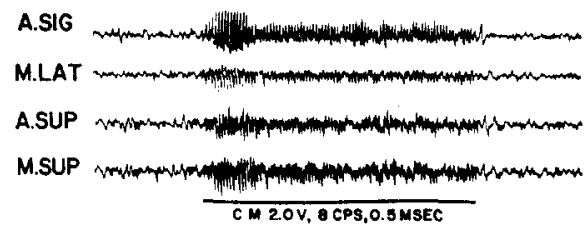

C. 30 MIN AFTER

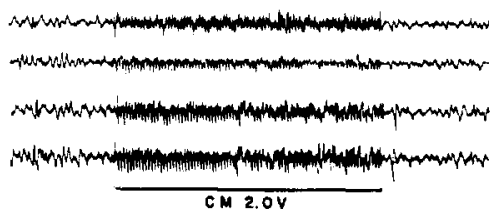

E. 5 MIN AFTER 6 MG/KG PENTOBARB.I.V.

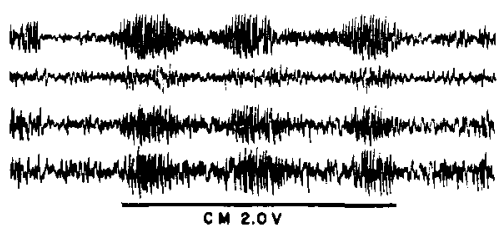

\section{5 MIN AFTER 2MG/KG KETAMINE I.V.}

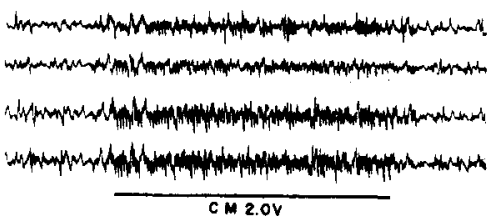

D. I H R AFTER

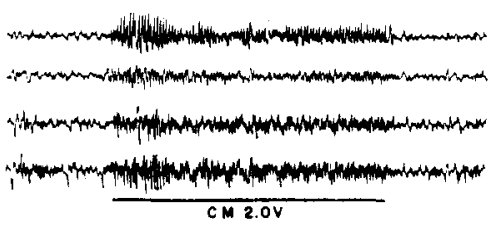

F. 5MIN AFTER I5 MG/KG PENTOBARB. I.V.

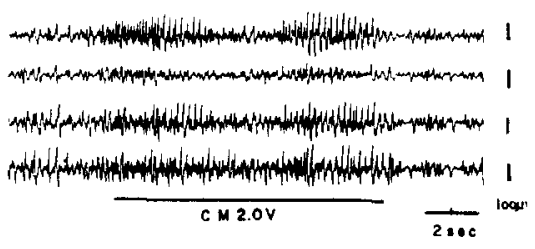

( CAT A. B)

FIG. 5. Comparative effects of ketamine and pentobarbital on the recruiting response.

Panel A. Control recruiting response elicited by stimulation of $\mathbf{n}$. centrum medianum. Panel B. $5 \mathrm{~min}$ after $2 \mathrm{mg} / \mathrm{kg}$ of ketamine i.v., this response is reduced. Panel C. $30 \mathrm{~min}$ after ketamine administration. Panel D. 1 hr after ketamine administration. The recruiting response recovered almost to control levels. Panel E. $5 \mathrm{~min}$ after $6 \mathrm{mg} / \mathrm{kg}$ of pentobarbital i.v., the response is distinctly enhanced. Panel F. $5 \mathrm{~min}$ after an additional $15 \mathrm{mg} / \mathrm{kg}$ of pentobarbital i.v., the recruiting response is still enhanced. 


\section{Effects of EEG activation}

The action of ketamine on EEG activation produced by threshold high frequency stimulation of the midbrain reticular formation and/or nucleus centrum medianum was studied in 12 animals. With $1 \mathrm{mg} / \mathrm{kg}$ i.v., EEG activation was not affected either in its threshold or duration in both the neocortical and limbic systems. Following $2 \mathrm{mg} / \mathrm{kg}$, the threshold of neocortical activation was not altered, although the duration was reduced to $\frac{1}{2}$ to $\frac{1}{4}$ of the control period (see Fig. 6C, D). Hippocampal activation responses were still present even

\section{A. CONTROL BY RF STIMULATION}

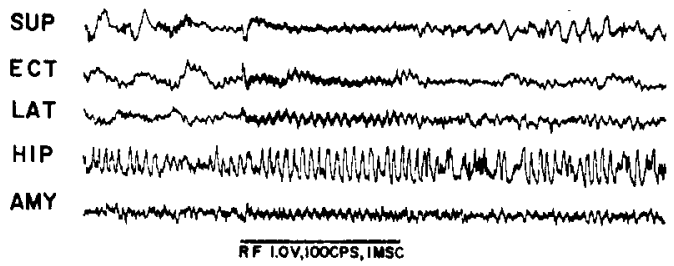

C. RF STIM. 5 MIN AFTER 2 MG/KG I.V.

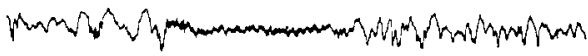

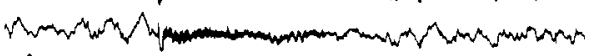

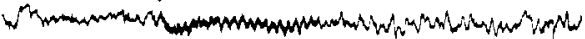

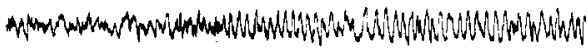

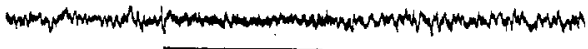

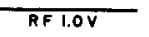

E. R F STIM. 5 MIN AFTER 4 MG/KG I.V.

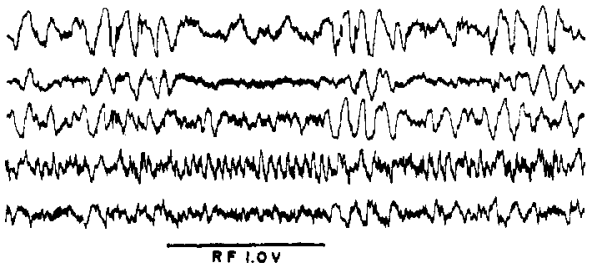

B. CONTROL BY CM STIMULATION

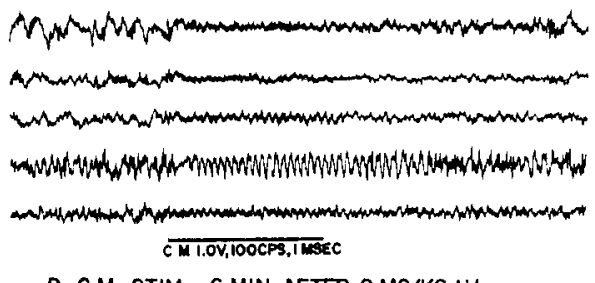

D. CM STIM. 6 MIN AFTER 2 MG/KG I.V.

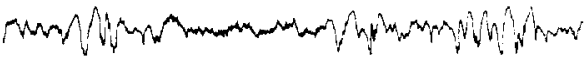

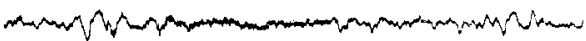

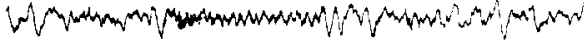

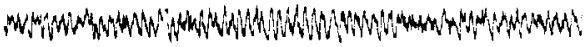

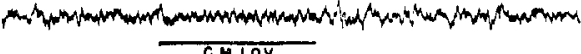

F. CM STIM. 6 MIN AFTER 4 MG/KG I.V.

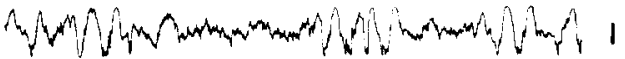

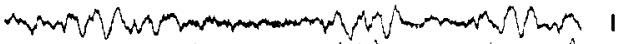

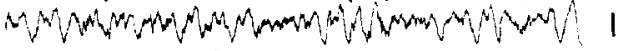

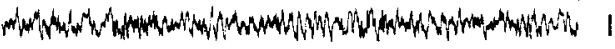

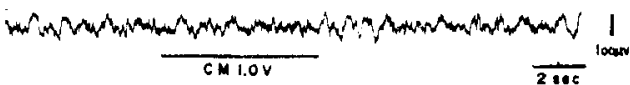

(CAT A. 22)

FIG. 6. Effects of ketamine on EEG activation.

Panels A and B. Control EEG activation elicited by a threshold stimulus to the midbrain reticular formation and $\mathrm{n}$. centrum medianum. Panels $C$ and $D$. 5 or $6 \mathrm{~min}$ after $2 \mathrm{mg} / \mathrm{kg}$ i.v. of ketamine, EEG activation is reduced in duration but the threshold is not altered. Panels $\mathrm{E}$ and $F$. 5 or $6 \mathrm{~min}$ after a total of $4 \mathrm{mg} / \mathrm{kg}$ of ketamine, EEG activation is shortened but still present. EEG activation responses produced by stimulation of the midbrain reticular formation and $n$. centrum medianum are only shortened in duration after minimal anesthetic doses of ketamine.

when the thalamo-neocortical slow waves reappeared indicating the dissociation of the neocortex and hippocampus. Following doses of $4 \mathrm{mg} / \mathrm{kg}$ of ketamine, the threshold of stimulation of the reticular formation or nucleus centrum medianum to cause EEG activation was not elevated, although the effects were limited to the period of stimulation (see Fig. 6E, F). Following $8 \mathrm{mg} / \mathrm{kg}$ of ketamine, desynchronization of the neocortex was reduced to the duration of reticular stimulation. Depending on the dose administered, recovery occurred within $45 \mathrm{~min}$ (after $2 \mathrm{mg} / \mathrm{kg}$ ) to $1-1.5 \mathrm{hr}$ (after $4-8 \mathrm{mg} / \mathrm{kg}$ ). In contrast to the less obvious 
depression of EEG activation by ketamine, doses of $10-20 \mathrm{mg} / \mathrm{kg}$ of pentobarbital or thiamylal produced marked suppression of EEG activation and elevation of the threshold for stimulation of both the reticular formation and nucleus centrum medianum.

\section{Effects on somatosensory evoked potentials}

Somatosensory evoked potentials produced by contralateral median nerve stimulation ( $1 \mathrm{~Hz}, 0 \cdot 2-0.3 \mathrm{msec}, 1 \cdot 5-4 \mathrm{~V}$ ) were recorded monopolarly and summated 100 times by the CAT computer. The results described were obtained in 15 animals. As illustrated in Figs. 7 and 8 , the evoked potentials consisted of sharp positive and blunt negative waves in the

A. KETAMINE, 3MG/IKG I.V.

(MEDIAL NERVE I.5V, I CPS, 0.2MSEC, IOOSTIM.)

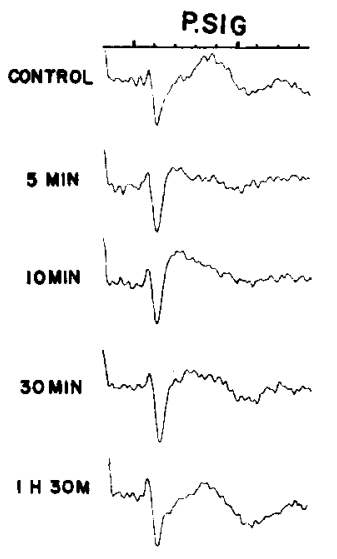

B. THIAMYLAL I5MG/KG I.V.
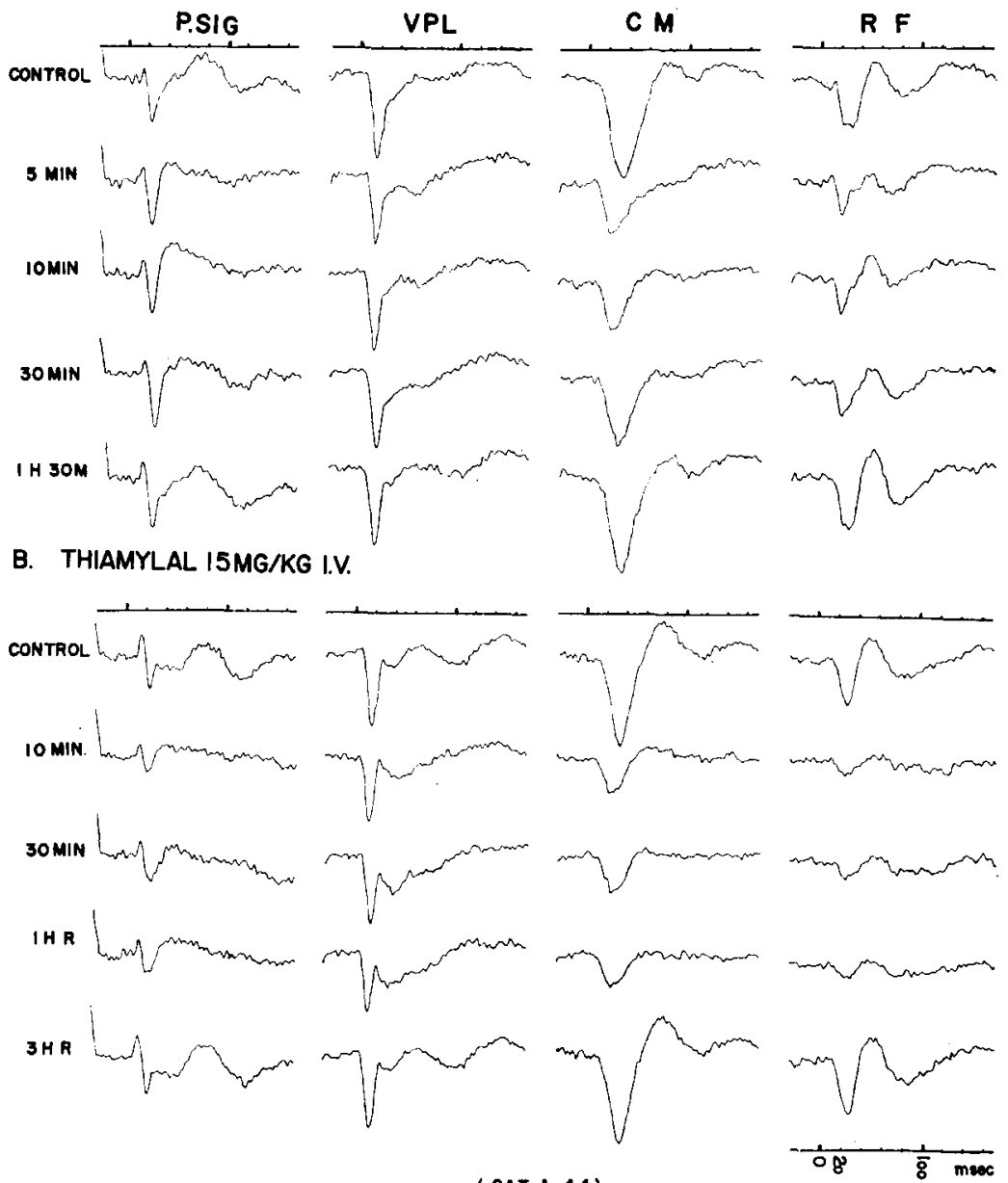

(CAT A. 44)

FIG. 7. Effects of ketamine and thiamylal on somatosensory evoked potentials.

Panel A. One hundred somatosensory evoked potentials were summated before and after various times following $3 \mathrm{mg} / \mathrm{kg}$ of ketamine i.v. Note that $5 \mathrm{~min}$ after ketamine administration, the potentials are reduced in all areas, but proportionately most in centrum medianum and next in the reticular formation. The negative components of the potentials are also depressed. Panel B. Effects of $15 \mathrm{mg} / \mathrm{kg}$ of thiamylal i.v. Note that following thiamylal administration, the sensory evoked potentials are depressed in most cases in the brain but most prominently in the reticular formation. Negativity is up in this and the subsequent illustration. 


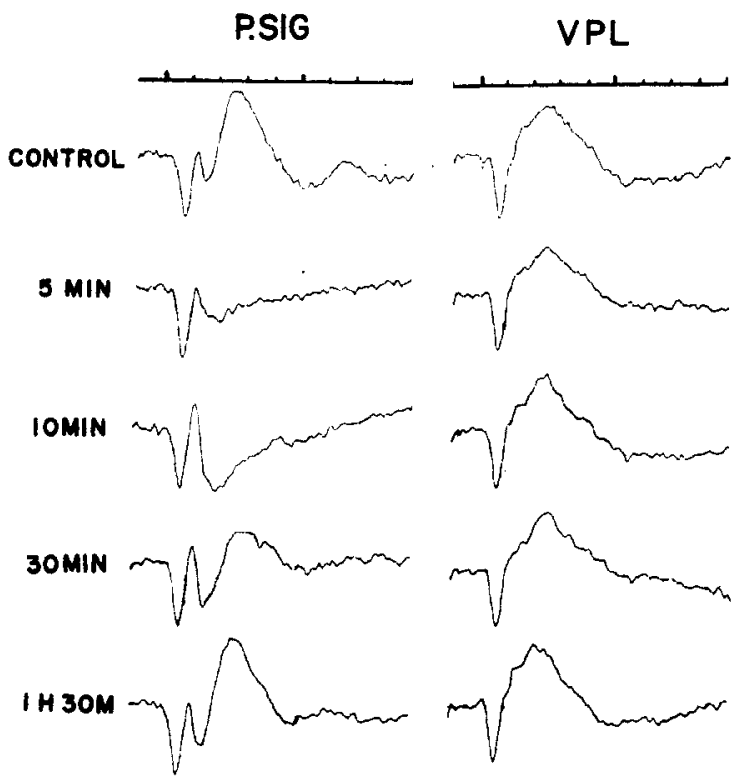

( MEDIAL NERVE, I.5V,I CPS, 0.3 SEC, 100STIM.)

( CAT A.3O)

FIG. 8. Effects of ketamine on somatosensory evoked potentials.

Note that ketamine $4 \mathrm{mg} / \mathrm{kg}$ i.v. reduced the negative component of the response in posterior sigmoid gyrus more dramatically than in the thalamic relay nucleus. Furthermore, the negative components are more suppressed than the initial positive waves. Note gradual recovery over the next $90 \mathrm{~min}$. Parameters of electrical stimulation are illustrated.

following four structures: posterior sigmoid gyrus (P.SIG), nucleus ventralis posterior lateralis of the thalamus (VPL), nucleus centrum medianum (CM), and midbrain reticular formation (RF). These waves generally persisted for as long as $150 \mathrm{msec}$ after stimulation. Comparing the rather stable primary positive components in the above mentioned four structures, ketamine (2-4 mg/ $/ \mathrm{kg}$ ) suppressed these potentials generally in VPL, CM, and RF. In P.SIG the positive component was suppressed only by the larger dose of $4 \mathrm{mg} / \mathrm{kg}$. It is of interest that the depression of the first positive component was greater in $\mathrm{CM}$ and RF than in P.SIG and VPL as might be expected. Furthermore, it was noticed with ketamine that the CM potential was more depressed than that in RF (see Fig. 7) in most of the preparations studied.

The secondary negative component of the somatosensory evoked potential was quite variable and even absent in some cases. When it was present, however, it was even more suppressed by ketamine than the first positive component, especially in the neocortex (Fig. 8).

In contrast to the effects induced by ketamine on somatosensory evoked potentials, thiamylal $(8-20 \mathrm{mg} / \mathrm{kg}$, i.v.) produced greater suppression of the evoked potential in the reticular formation than in CM (Fig. 7).

Effects on multiple unit activity

Multiple unic activity (SChlag and Balvin, 1963; Weber and BuchWALd, 1965; GoodMAN and MANN, 1967; Podvoll and GoOdMAN, 1967) was recorded from the same electrodes 
as used for EEG recording in CM, VPL, RF, and the neocortex in 12 animals. The neuronal activity consisted of continuous multiple units of approximately $15-20 \mu \mathrm{V}$ in amplitude in the thalamus and reticular formation. The noise level of the system was approximately 4-6 $\mu \mathrm{V}$. Multiple unit discharge increased in amplitude during EEG activation and showed a high voltage grouping corresponding to the evoked potentials induced by sensory stimuli in the thalamus and reticular formation.

The correlation between multiple unit activity and EEG changes produced by $2-4 \mathrm{mg} / \mathrm{kg}$ of ketamine was studied in detail. During the delta wave phase induced by ketamine, the neuronal activity in CM and VPL showed remarkable grouping with a close phase relationship with the EEG (see Fig. $9 \mathrm{CM}$ ). Neuronal grouping of activity in CM and VPL was

CONTROL
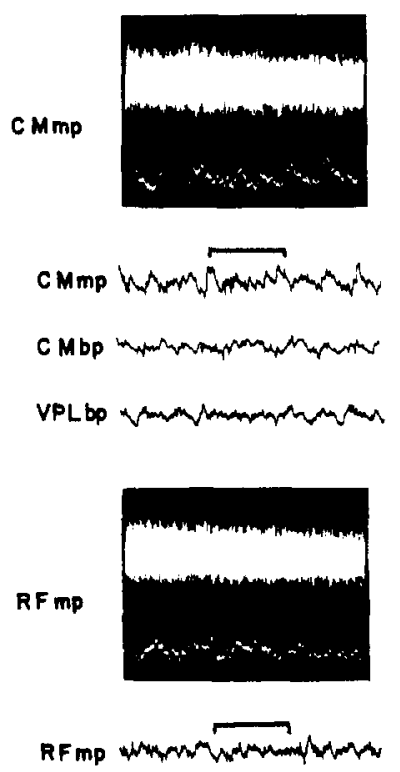

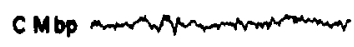

VPLbp anm ansm
SMIN AFTER KETAMINE 4 MG/KGIV.
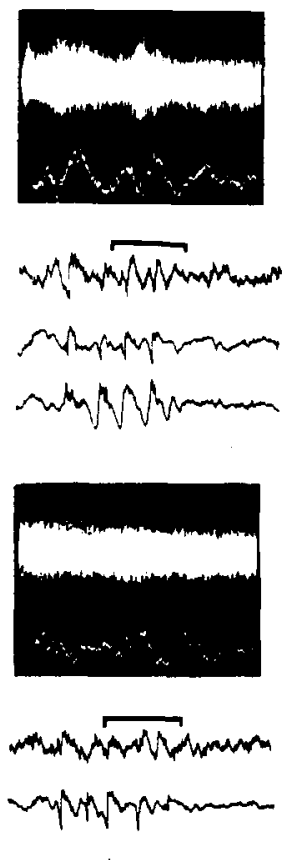

ravinumen
Q MIN AFTER
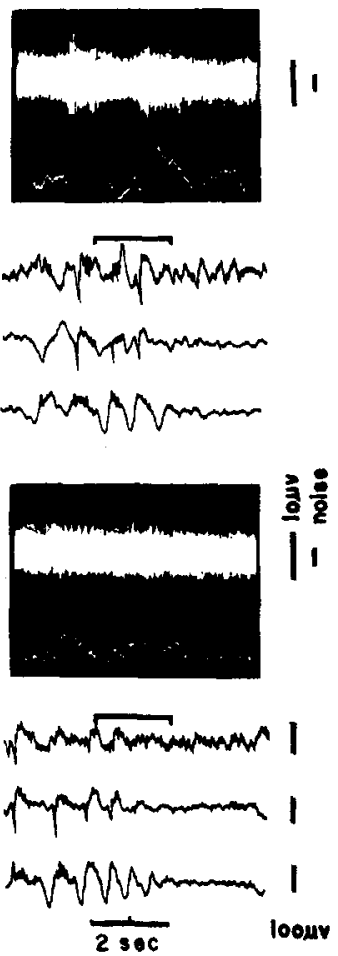

(CAT. A.59)

FIG. 9. Effects of ketamine on multiple unit activity and EEG delta waves.

Each panel consists of the photographed multiple unit and EEG activity from either $n$. centrum medianum or the reticular formation. Below this appears the EEG activity recorded in a conventional manner. The length of the bar below indicates the period in which the multiple unit activity was recorded. MP designates monopolar recording and BP bipolar recording. Note that in the control period, multiple unit activity has a relatively high baseline, seemingly unrelated to spontaneous EEG activity. Similarly, in the control tracing recorded from the reticular formation, a high baseline of multiple unit activity is seen. Five min after $4 \mathrm{mg} / \mathrm{kg}$ i.v. ketamine administration, multiple unit activity in $\mathbf{n}$. centrum medianum showed a grouping closely related to the centrum medianum bipolar recording but poorly related to the centrum medianum monopolar recording. In contrast, the reticular formation at this time showed none of the characteristic grouping of the neuronal activity seen in the thalamus. Note also that the total amplitude of multiple unit activity was not greatly affected. 8 min after ketamine administration, the same phenomenon of grouping of multiple unit activity in $\mathbf{n}$. centrum medianum persisted. 
pronounced with the peaks and troughs closely related to the delta waves. Before ketamine the neuronal activity was of constant amplitude and asynchronous. After ketamine the peak amplitude exceeded the mean control amplitude, while the amplitude of the troughs was smaller than control. During the interrupting fast-wave phase, neuronal activity of $\mathrm{CM}$ and VPL was somewhat smaller than during the control period.

In the midbrain reticular formation, the neuronal activity did not show any characteristic grouping during the delta wave phase. The neuronal activity was almost at the same amplitude level following ketamine or only slightly decreased (see Fig. 9, RF). Likewise hypothalamic neuronal activity did not show any characteristic amplitude modulation.

The amplitude of multiple unit activity in the neocortex was close to the noise level, in contrast to the much larger amplitudes recorded in the subcortical structures. No significant changes could be observed by this method because of the inadequacy of the recordings.

Of particular importance was the fact that there was a close relationship between the multiple unit burst patterns and the form of the EEG slow waves especially in n. centrum

CONTROL
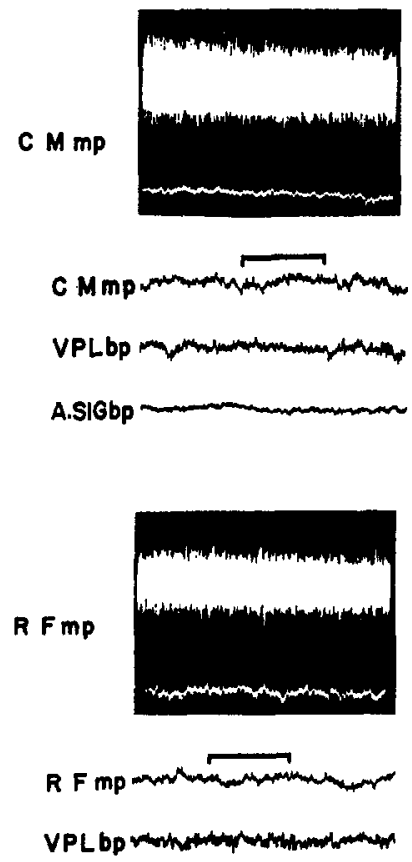

A.SIGbp
THIAMYLAL 2OMG/KG I.V.
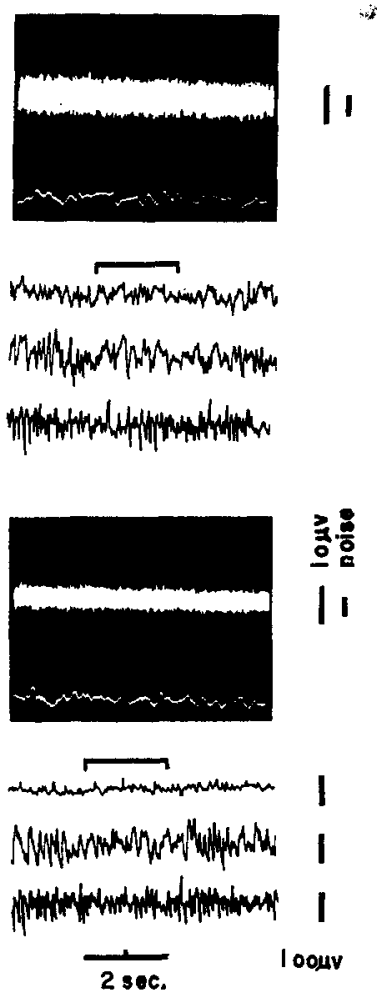

(CAT A. 57 )

FIG. 10. Effects of thiamylal on multiple unit activity and EEG.

The format of this illustration is similar to that of Fig. 9. During the control period, a high level of multiple activity was observed in both $n$. centrum medianum and the reticular formation while the EEG showed low voltage, fast frequency activity. $8 \mathrm{~min}$ after $20 \mathrm{mg} / \mathrm{kg}$ of thiamylal i.v., multiple unit activity was markedly suppressed in both the thalamus and reticular formation. The suppression of the neuronal activity in the reticular formation was marked, almost to the noise level. 
medianum. An especially important variable was whether monopolar or bipolar recordings were used. With monopolar EEG recordings there was much less association between slow-waves and multiple unit activity as might be expected. In contrast, close bipolar EEG recordings showed much closer correlation with the neuronal activity. It was noted that bursts of neuronal activity corresponded to the positive sharp clefts justs preceding negative slow waves in the monopolar EEG of the same electrode in the thalamus. This grouping corresponded more clearly to the prominent peaks of the sharp slow waves in the bipolar EEG of $n$. centrum medianum (Fig. 9, CM). The peaks of the neuronal bursts of $n$. centrum medianum corresponded to the deep cleft followed by large delta waves in the EEC of the neocortex.

Similarly, the neuronal discharge patterns from $\mathrm{n}$. ventralis posterior lateralis usually corresponded to portions of the slow waves recorded in the same place, particularly with bipolar recordings. However, even in this nucleus, burst patterns frequently correlated more clearly with the sharp slow waves recorded in the bipolar EEG of n. centrum medianum.

The i.v. administration of $10-20 \mathrm{mg} / \mathrm{kg}$ of pentobarbital or thiamylal in preanesthetic or minimal anesthetic dosage depressed the amplitude of spontaneous neuronal discharges in the reticular formation and thalamus to a much greater extent than anesthetic doses of ketamine (2-4 mg/kg). As shown in Fig. 10, neuronal activity in RF was markedly depressed by thiamylal in contrast to that in CM or VPL. Multiple unit discharge in the reticular formation was more depressed by barbiturates than in the thalamus. In contrast, ketamine modulated multiple unit activity at the thalamic level with little effect on the reticular formation.

\section{DISCUSSION}

In anesthetic doses in man, ketamine produces fairly continuous theta waves and rarely delta wave bursts (Domino et al., 1965; ViRTuE et al., 1967). In the present experiments in cats, the alternating pattern of hypersynchronous delta wave bursts and low voltage, fast wave activity was observed consistently with anesthetic doses of ketamine primarily in the thalamus and neocortex. These prominent EEG changes in the cat were very similar to the EEG patterns observed in the neocortex of animals given phencyclidine, a closely related congener of ketamine (Domino, 1964).

After ketamine the thalamus showed a synchronous relationship with the neocortex in the alternating EEG pattern of high voltage, delta wave bursts and low voltage, fast wave activity. The diffuse thalamic projection system, especially $n$. centrum medianum, showed sharp, slow waves followed by delta waves in the neocortex and thalamic sensory relay nuclei. The delta wave bursts usually appeared after suppression of spindle bursts and showed a similar distribution in the neocortex to spindles (MORISON and DEMPSY, 1942). This fact suggests a predominant involvement of a thalamo-neocortical reverberating circuit. This is in line with the widely held concept that spindle bursts and slow waves are dependent on the activity of the nonspecific thalamo-neocortical circuit (RALSTON and AJMONE-MARSAN, 1956; BREMER, 1958; BUSER, 1964; JASPER, 1965).

Ketamine-induced delta wave bursts were not prominent in the midbrain reticular formation and hypothalamus. Furthermore, the hippocampus showed the typical theta activity of "arousal," in spite of the appearance of high voltage, delta wave bursts in the thalamus and neocortex. The hippocampal "arousal" waves appeared more activated than during the control period, especially at the end of the delta wave burst period. Behaviorally 
this corresponded to a drunk-like, restless and excited state, which might be interpreted as the period of emergence delerium. This prominent EEG dissociation between the neocortex and the limbic system might be involved in the mechanism of its psychotomimetic action. A similar type of EEG dissociation has been observed with ethyl alcohol (KoGI et al., 1960), except that neocortical delta waves were more persistent after ketamine.

The recruiting response produced by centrum medianum stimulation was suppressed by ketamine in both preanesthetic and anesthetic doses. In contrast, EEG activation produced by stimulation of the reticular formation or centrum medianum was barely altered by ketamine. The recruiting and activation responses elicited by stimulation of the diffuse thalamic projection nuclei are mediated by different pathways. The former is thought to be mediated through the reticular nucleus to the neocortex, while the latter backward through the midbrain reticular formation (SCHLAG and CHAILLET, 1963; WeINBERGER et al., 1965). Ketamine seems to suppress mainly the diffuse thalamo-neocortical projection system with less of an effect on the reticular-neocortical activating system. This is in marked contrast to the effects of barbiturates on these systems as described previously (DOMINo, 1955; KING, 1956; Killam, 1962). These effects of ketamine on recruiting the activating responses are somewhat similar but not identical to the action of diethyl ether (DOMINO, 1955; BraziER, 1961).

In both the cerveau isolé and subtotally decorticated preparations, moderate to high voltage delta waves were recorded after ketamine in the thalamus, although the delta waves did not have clear burst-forms compared to those observed in the intact brain. It is apparent that the reticular activating system is not critical for the presence of delta wave bursts in the intact brain, but it is involved in the production of delta bursts by interrupting the delta waves with low voltage, fast wave activity. The neocortical part of the reverberating circuit is not essential for production of delta waves, but is necessary for producing clear bursts of high-voltage, delta waves in a similar manner to the bursts of spindles.

The primary positive components of the somatosensory evoked potentials were more constantly and conspicuously suppressed by ketamine in centrum medianum and the reticular formation than in the neocortex and $n$. ventralis posterior lateralis. This prominent susceptibility of the nonspecific thalamic system is similar to that observed following barbiturate anesthesia (French et al., 1953; Collins and O'Leary, 1954; King, 1956; Killam, 1962; BRAZIER, 1961). Although the evoked potentials were depressed in both centrum medianum and the reticular formation, the centrum medianum appeared to be more suppressed in 5 of 7 cats. These results were not statistically significant across all animals, but they were sufficiently consistent to merit comment. In general, it appears that the diffusely projecting thalamic system and midbrain reticular formation may show some differential susceptibility to different kinds of general anesthetics. For example, BrazIER (1961) has pointed out that barbiturates suppress the evoked potential more in the reticular formation than in centrum medianum, while diethyl ether has a greater depressant effect on responses recorded in centrum medianum. Similarly, ARDUINI (1958) reported that the neocortical surface negative slow potential produced by the reticular formation was depressed by barbiturate anesthesia, but responses produced by thalamic stimulation (both medial and lateral) were not. Brazier has postulated that diethyl ether exerts its major depressant effects at the level of the midline thalamus because it suppresses evoked potentials in centrum medianum as well as the neocortical recruiting response elicited from stimulation of this area. Along similar lines, on the basis of the evidence obtained in our study, it appears that ketamine has a stronger depressant effect on the diffuse thalamic projection system than on the midbrain 
reticular formation. It was frequently observed that the negative components of the somatosensory evoked response were more suppressed than the initial positive wave. A similar phenomenon was observed on cortical evoked potentials recorded in the rabbit (Domino, 1964) following administration of phencyclidine. The corresponding somatosensory evoked potentials in the specific relay nucleus of the thalamus, ventralis posterior lateralis, were less influenced by ketamine. It is of interest that ANOKHIN (1964) and JANKOWSKA and AlBE-FESSARD (1961) have offered evidence that the initial positive potentials in the sensory cortex are produced in the deeper neocortical layers by specific thalamic volleys. On the other hand, the subsequent negative potentials appear to originate in the superficial apical dendritic layers by the nonspecific ascending thalamo-reticular system. On this basis, the greater effect of ketamine on the negative potentials of the somatosensory evoked response might be interpreted as a depression of the diffuse thalamic projection system at a thalamic and/or neocortical level.

Following anesthetic doses of ketamine, multiple unit activity showed a clear grouping in both specific and nonspecific thalamic nuclei in synchronous relation with delta waves recorded in the same structures and in the neocortex. The grouping of neuronal activity in $n$. centrum medianum showed the closest basic relationship with the EEG, especially with bipolar EEG recordings in the $\mathrm{n}$. centrum medianum which were constantly followed by neocortical delta waves. The neuronal activity in the reticular formation and hypothalamus showed relatively little change without suppression or grouping in contrast with their strong suppression following subanesthetic as well as anesthetic doses of the barbiturates. It should be pointed out that ketamine merely accentuated the synchronous firing of multiple units in the thalamus rather than completely suppressing them.

KNOTT et al. (1955) pointed out that the diffusely projecting thalamic system is important to the production of delta waves in the neocortex. This was based on evidence that lesions of the diffuse thalamic projection nuclei produced persistent EEG slow waves in the neocortex. Lesions of specific sensory relay nuclei did not produce prominent EEG changes. However, NAKAMURA and OHYE (1964) reported that the specific relay nuclei are also important for the projection of delta waves and postulated that the posterior hypothalamus exerted a strong suppressing action upon delta wave activity via the specific sensory nuclei to sensory cortex. The delta waves induced by ketamine do not appear to depend upon suppression of the latter system, since evoked potentials in the specific relay thalamic nuclei were minimally affected and the hypothalamic hippocampal activating system (TOKIZANE et al., 1960) was not significantly suppressed by this drug.

Our findings on EEG and multiple unit activity suggest that the diffuse thalamo-neocortical projecting system appears to be the primary site of action of ketamine. This would be consistent with the observation (MCCARThy et al., 1965; Domino et al., 1955; Chen et al., 1966: CORSSEN and Domino, 1966) that primates, having greater development of the neocortical system, show a greater susceptibility to the anesthetic actions of ketamine. Ketamine anesthesia differs markedly from that induced by barbiturates by lacking a strong depressant effect on multiple unit activity in the reticular formation. Thus, this anesthetic may have characteristics similar to those reported by WINTERS et al. (1967) for gamma hydroxybutyric acid and alpha chloralose.

The relationship between spontaneous EEG changes and neuronal activity has often been studied in connection with neocortical EEG spindles using microelectrode techniques. Much less is known about the relationship of delta waves to neuronal unit discharge. VERZEANO and CALMA (1954) observed a close and constant relationship between the slow waves 
of spontaneous and barbiturate-induced spindle bursts and unit activity in nonspecific thalamic nuclei. Their experiments showed groups of unitary spikes followed immediately by the positive phase of the slow-wave of the spindle. These investigators thought that the positive phase of the spindle bursts might be due to summation of positive after-potentials of neuronal spikes. JASPER (1965) also described the close relationship of the neuronal discharge and EEG slow waves in the recruiting response. In his study, a grouping of neuronal discharges appeared in neurons of deep cortical layers on the negative crest of the surface recruiting response. These waves did not appear to be due to a simple summation of neuronal discharges. The depolarization of the neurons in the recruiting response had to reach a critical threshold before grouping of self-discharges appeared. Furthermore, neuronal units fired even after the depolarization had reached a critical level below threshold. CREUTZFELDT et al. (1961) observed a more remarkable correlation between neuronal discharges and EEG activity in neocortical neurons following diethyl ether or cyclopropane anesthesia than after barbiturates. Groups of 4-8 neuronal discharges occurred synchronously with the biphasic or positive delta waves that are characteristic of deep diethyl ether anesthesia. Schlag (1956) also observed a close relationship between EEG and unit activity in spindle waves, but thought these were two independent phenomena because their relationship was not constant. Buchwald et al. (1966) observed no clear cut relationship between EEG and neuronal unit discharge except during large amplitude, rhythmic, EEG slow waves. AJMONE-MARSAN (1965) has reviewed this entire problem in detail. Slow wave EEG activity and neuronal discharge are indeed closely related. He has concluded that slow potential changes were either directly responsible for or secondary to neuronal unit discharge. In our own experiments, following ketamine, a constant phase relationship between multiple unit discharge and delta wave activity was clearly observed, especially in bipolar recordings in diffusely projecting thalamic nuclei. Our own experience with attempting to correlate multiple unit activity with EEG slow waves supports the conclusions of AJMONE-MARSAN that technical considerations are all important in obtaining a close relationship.

Acknowledgements-This work was supported in part by Grant MY-02653, USPHS.

M. Miyasaka is a Fulbright Exchange Scholar from the Department of Neuro-psychiatry, Tokyo Medical and Dental University, Tokyo, Japan.

\section{REFERENCES}

Ajmone-MARSAN, C. (1965). Electrical activity of the brain: Slow waves and neuronal activity. Israel J. med. Sci. 1: 104-117.

ANOKHIN, P. K.(1964). The clectroencephalogram as a resultant of ascending influences on the cells of the cortex. Electroenceph. clin. Neurophysiol. 16: 27-43.

Arduini, A. (1958). Enduring potential changes evoked in the cerebral cortex by stimulation of brain stem reticular formation and thalamus. In Reficular Formation of the Brain, JASPER, H. H., Procter, L. D., Knightson, R. S., Noshay, W. C. and Costello, R. T., (eds.), pp. 333-351. Little Brown, Boston.

BRAZIER, M. A. B. (1961). Some effects of anaesthesia on the brain. Brit. J. Anaesth. 33: 194-204.

Brif, M. M., Feller, 1. and Corssen, G. (1967). Safety and tolerance of repeated anesthesia with Cl-581 (Ketamine) in monkeys. Anesth. Analg. (Cleveland) 46: 596-600.

Bremer, F. (1958). Cerebral and cerebellar potentials. Physiol. Rev. 38: 357-388.

Buchwald, J. S., Halas, E. S. and Schramm, S. (1966). Relationships of neuronal spike populations and EEG activity in chronic cats. Electroenceph. clin. Neurophysiol. 21: 227-238.

Buser, P. (1964). Thalamic influences of the EEG. Electroenceph. clin. Neurophysiol. 16: 18-26.

Chen, G., ENsor, C. R. and BoHner, B. (1966). The neuropharmacology of 2-(0-chlorophenyl)-2-methylaminocyclohexanone hydrochloride. J. Pharmac. exp. Ther. 152: 332-339. 
Collins, W. F. and O'Leary, J. L. (1954). Study of a somatic evoked response of midbrain reticular substance. Electroenceph. clin. Neurophysiol. 6: 619-628.

Corssen, G. and Domino, E. F. (1966). Dissociative anesthesia: Further pharmacologic studies and first clinical experience with the phencyclidine derivative CI-581. Anesth. Analg. (Cleveland) 45: 29-40.

Creutzfeldt, O., Bark, J. and Fromm, G. H. (1961). Alterations in activity of cortical neurones during anesthesia compared with hypoxia. In Cerebral Anoxia and the Electroencephalogram, GaSTAUT, H. and MeYER, J. S., (eds.), pp. 35-45. Thomas, Springfield.

Domino, E. F. (1955). A pharmacological analysis of the functional relationship between the brain stem arousal and diffuse thalamic projection systems. J. Pharmac. exp. Ther. 115: 449-463.

Domino, E. F. (1964). Neurobiology of phencyclidine (Sernyl), a drug with an unusual spectrum of pharmacological activity. Int. Rev. Neurobiol. 6: 303-347.

Domino, E. F., Chodoff, P. and Corssen, G. (1965). Pharmacologic effects of CI-581, a new dissociative anesthetic, in man. Clin. Pharmac. Ther. 6: 279-291.

French, J. D., Verzeano, M. and Magoun, H. W. (1953). A neural basis of the anesthetic state. $A M A a r c h$. Neurol. Psychiat. 69: 519-529.

Goodman, S. J. and MANN, P. E. G. (1967). Reticular and thalamic multiple unit activity during wakefulness, sleep and anesthesia. Exp. Neurol. 19:11-24.

Jasper, H. H. and Ajmone-Marsan, C. (1954). A Stereotaxic Atlas of the Diencephalon of the Cat. National Research Council of Canada, Ottawa.

JASPER, H. (1965). Reticular-cortical systems and theories of the integrative action of the brain. In Biological and Biochemical Bases of Behavior, HARLOW, H. F. and WoOLSEY, C. N., (eds.), pp. 37-61. University of Wisconsin Press.

JANkowska, E. and Albe-Fessard, D. (1961). Sur l'origine et l'interpretation de la seconde phase du potentiel evoque primaire de l'aire somatique. J. Physiol, Paris 53:374-375.

Killam, E. K. (1962). Drug action on the brain-stem reticular formation. Pharmac. Rev. 14: 175 223.

KING, E. E. (1956). Differential action of anesthetics and interneuron depressants upon EEG arousal and recruitment responses. J. Pharmac.exp. Ther. 116:404-417.

Knott, J. R., Ingram, W. R. and Chiles, W. D. (1955). Effects of subcortical lesions on cortical electroencephalogram in cats. A.M.A. Arch. Neurol. Psychiat. 73:203-215.

Kogi, K., Nakamura, T., Miyama, T. and Kawamura, H. (1960). Effect of ethyl alcohol on electrical activity neo-, paleo- and archicortical system. Ann. Rep. Inst. Sci. Lab., Kurashiki 56: 1-14.

McCarthy, D. A., Chen, G., Kaump, D. H. and Ensor, C. (1965). General anesthetic and other pharnacological properties of 2-(0-chlorophenyl)-2-methylamino cyclohexanone $\mathrm{HCl}$ (CI-581), J. new Drugs 5: $21-33$.

Morison, R. S. and Dempsey, E. W. (1942). A study of thalamo-cortical relations. Am.J. Physiol. 135: 281292.

Nakamura, Y. and OHYE, C. (1964). Delta wave production in neocortical EEG by acute lesions within thalamus and hypothalamus of the cat. Electroenceph. clin. Neurophysiol. 17: 677-684.

Podvoll, E. M. and Goodman, S. J. (1967). Averaged neural electrical activity and arousal. Science, N. Y. 155: $223-225$.

Ralston, B. and AJMONE-Marsan, C. (1956). Thalamic control of certain normal and abnormal cortical rhythms. Electroenceph. clin. Neurophysiol. 8: 559-582.

SCHLAG, J. (1956). A study of the action of nembutal on diencephalic and mesencephalic unit activity. Arch. int Physiol. 64: 470-488.

Schlag, J.and Balvin, R. (1963). Background activity in the cerebral cortex and reticular formation in relation with the electroencephalogram. Exp. Neurol. 8: 203-219.

Schlag, J. D. and Chaillet, F. (1963). Thalamic mechanisms involved in cortical desynchronization and recruiting responses. Electroenceph. clin. Neurophysiol. 15: 39-62.

Snider, R. S. and Niemer, W. T. (1961). A Stereotaxic Atlas of the Cat Brain. The University of Chicago Press.

Tokizane, T., Kawamura, H. and Imamura, G. (1960). Hypothalamic activation upon electrical activities of paleo- and archicortex. Neurol. medico-chir. 2: 63-76.

Verzeano, M. and Calma, L. (1954). Unit activity in spindle bursts. J. Neurophysiol. 17: 417-428.

Virtue, R. W., Alanis, J. M., Mori, M., Lafargue, R. T., Vogel, J. H. K. and Metcalf, D. R. (1967). An anesthetic agent: 2-orthochlorophenyl, 2-methylamino cyclohexanone CI-581. Anesthesiology 28: $823-833$.

WEBER, D. S. and BuCHWALd, J. S. (1965). A technique for recording and integrating multiple activity simultaneously with the EEG in chronic animals. Electroenceph. clin. Neurophysiol. 19: 190-192.

Weinberger, N. M., Velasco, M. and Lindsley, D. B. (1965). Effects of lesions upon thalamically induced electrocortical desynchronization and recruiting. Electroenceph. clin. Neurophysiol. 18: 369-377.

Winters, W. D., Mori, K., Spooner, C. E. and Bauer, R. O. (1967). The neurophysiology of anesthesia. Anesthesiology 28: 65-80. 